\title{
Effects of postnatal lead acetate exposure on activity and emotionality in developing laboratory rats
}

\author{
CHARLES R. GEIST and STANLEY W. BALKO \\ University of Alaska, Fairbanks, Alaska 99701
}

\begin{abstract}
At 21 days of age three groups of female hooded rats were exposed to lead at concentrations of $0 \mathrm{ppm}, 25 \mathrm{ppm}$, or $50 \mathrm{ppm}$ provided ad lib in the acetate form for 35 days in the drinking water. No significant differences were found in food consumption, lead acetate or water consumption, and weight gain. When subjects were tested in an open-field task, no significant differences were found in either the duration or frequency of grooming or rearing behavior, or the number of squares traversed. However, significant differences in emotionality were observed. Subjects receiving $50 \mathrm{ppm}$ lead acetate exhibited markedly greater emotionality when compared with subjects receiving either $25 \mathrm{ppm}$ lead acetate or $0 \mathrm{ppm}$ lead acetate. The results appear to indicate that postnatal lead exposure may affect some elements of emotional behavior, while having little effect on activity.
\end{abstract}

Marked effects on behavior and learning have been demonstrated in animals following exposure to inorganic lead during the prenatal or developing neonatal periods at dosages lower than those necessary to cause encephalopathy (Brown, 1975; Driscoll \& Stegner, 1976; Winneke, Brockhaus, \& Baltissen, 1977). However, especially equivocal results exist regarding hyperactivity, which has been reported in children (David, 1974), as well as in rats (Golter \& Michaelson, 1975; Sauerhoff \& Michaelson, 1973; Winneke et al., 1977) and mice (Silbergeld \& Goldberg, 1974a, 1974b). By way of opposition, Hastings, Cooper, Bornschein, and Michaelson (1977), Rafales, Bornschein, Michaelson, Loch, and Barker (1979), and Sobotka and Cook (1974) failed to find evidence of hyperactivity. Moreover, Driscoll and Stegner (1976) and Reiter, Anderson, Laskey, and Cahill (1975) have reported hypoactivity.

Investigations of the effects of lead exposure on the behavioral repertoire of postweanling and adult animals appear conspicuously lacking in the literature. For the most part, the small number of studies have shown an increased variability of performance, with few significant effects (Brown, Dragann, \& Vogel, 1971; Snowdon, 1973). However, Lanthorn and Isaacson (1978) described an exaggerated and heightened responsiveness, as well as reduced rates of spontaneous alternation, and Geist and Mattes (1979) reported learning deficits in rats postnatally exposed to lead acetate.

Because of the growing concern in recent years regarding the prevalence of lead in the environment and the possible subclinical effects resultant from sublethal postnatal lead exposure, the following investigation of activity and emotionality was undertaken to address the question of intoxication effects due to the presence of lead burden in soft tissue.

\section{METHOD}

\section{Subjects}

The subjects of the present investigation consisted of 18 female hooded rats bred at the University of Alaska. All subjects were housed individually in standard stainless steel laboratory cages measuring $17.8 \times 24.5 \times 17.8 \mathrm{~cm}$. Purina Rodent Laboratory Chow 5001 (St. Louis, Missouri) and water, with or without lead acetate, were provided ad lib in the home cage. The animals were maintained on a 12-h light-dark cycle commencing at $0800 \mathrm{~h}$. The laboratory temperature was maintained at $22.5^{\circ} \mathrm{C} \pm 2^{\circ} \mathrm{C}$, with moderate humidity.

\section{Procedure}

At 21 days of age, the subjects were randomly assigned to one of three treatment groups: $0 \mathrm{ppm}, 25 \mathrm{ppm}$, or $50 \mathrm{ppm}$ lead administered in the acetate form in the drinking water. The lead acetate was dissolved in distilled deionized water and provided ad lib from 21 days of age throughout the duration of the experiment. Testing in the open field began 35 days following the initial exposure to lead acetate in order to facilitate an accumulation of lead concentration to a steady-state level (Castellino \& Aloj, 1964). Due to the development of an eye infection in a single animal in the group receiving $50 \mathrm{ppm}$ lead acetate just postweaning, this subject was excepted from further behavioral study. Food consumption, lead acetate or water consumption, and weight gain were recorded every 3 days throughout the experiment.

At 56 days of age the subjects were placed for $5 \mathrm{~min} / \mathrm{animal}$ into an open field measuring $91.4 \times 91.4 \times 30.5 \mathrm{~cm}$ that had been marked off into $7.6-\mathrm{cm}$ squares. Testing continued daily for 5 days. Duration and frequency of grooming and rearing, as well as the number of squares traversed, boli excreted, and urinations, were recorded during the 5 -min interval under each condition.

For all of the behavioral data collected, excluding food consumption, lead acetate or water consumption, and weight gain, treatment level means and variances tended to be proportional. Hence, the data were normalized prior to analysis by applying a square-root transformation after adding .5 to each of the data points as a correction for data values less than 10 (Kirk, 1968). 


\section{RESULTS}

The effects of dietary lead acetate treatment on growth, expressed in terms of body weight, food consumption, and lead acetate or water consumption, were determined by means of an analysis of variance. No significant differences were found among the three treatment groups on these measures as a function of dietary lead acetate concentration $[\mathrm{F}(2,14)=.074$, $\mathrm{p}>.90 ; \mathrm{F}(2,14)=.058, \mathrm{p}>.90 ;$ and $\mathrm{F}(2,14)=.150$, $\mathrm{p}>.80$, respectively] . Regardless of treatment, however, significant differences were found across days for body weight, as shown by mean values of $23.49,30.50$, $41.89,53.90,68.92,82.86,96.31,108.87,119.73$, and $130.34 \mathrm{~g}[\mathrm{~F}(9,126)=206.010, \mathrm{p}<.001]$; lead acetate or water consumption, with mean values of 22.29 , $42.28,48.30,55.22,66.78,68.28,75.16,76.35$, and $82.38 \mathrm{~g} \quad[\mathrm{~F}(8,112)=66.229, \quad \mathrm{p}<.001] ;$ and food consumption, with mean values of $19.54,27.96,31.64$, $41.56,45.29,49.32,52.96,53.68,55.58 \mathrm{~g}[\mathrm{~F}(8,112)=$ $95.230, \mathrm{p}<.001]$.

An analysis of variance of the transformed values of grooming behavior yielded no significant differences as a function of dietary lead acetate for either duration of grooming $[F(2,14)=.587, \mathrm{p}>.50]$ or frequency of grooming $[F(2,14)=.074, p>.90]$. Irrespective of treatment, though, significant differences were found across days of testing for both duration, as evidenced by transformed trial means of $2.78,4.55,4.44,4.87$, and $4.82 \mathrm{sec}[\mathrm{F}(4,56)=4.110, \mathrm{p}<.01]$, and frequency, with transformed trial means of $1.66,2.19,2.19$, 2.27 , and $2.18[F(4,56)=2.170, p<.05]$. Both variables of grooming stabilized at relatively higher values following Day 1 performance. The increase in performance from Day 1 to Day 2 was found to be significantly different for both duration $[\mathrm{t}(56)=2.940, \mathrm{p}<.01]$ and frequency $[\mathrm{t}(56)=2.500, \mathrm{p}<.05]$.

The analysis of variance of the transformed values of rearing behavior also showed no significant differences as a function of dietary lead concentration for either duration of rearing $[\mathrm{F}(2,14)=1.080, \mathrm{p}>.30]$ or frequency of rearing $[\mathrm{F}(2,14)=.471, \mathrm{p}>.60]$. Again, however, significant differences were found across days of testing for both duration, as shown by transformed trial means of $3.79,4.62,5.01,5.72$, and $6.08 \mathrm{sec}$ $[F(4,56)=7.921, \mathrm{p}<.001]$, and frequency, with transformed trial means of $3.27,3.79,4.00,4.48$, and 4.84 $[F(4,56)=6.270, p<.001]$. All subjects exhibited steadily increasing durations and frequencies of rearing from Day 1 to Day 5.

Analysis of variance of the transformed activity scores, in terms of the number of squares traversed, revealed no significant differences for the dietary lead conditions $[F(2,14)=.750, p>.50]$. All subjects, however, traversed significantly greater numbers of squares from Day 1 to Day 5 of testing, as evidenced by transformed trial means of $7.01,9.46,9.47,9.70$, and 11.36 $[\mathrm{F}(4,56)=5.901, \mathrm{p}<.001]$.
In assessing emotionality, the total number of boli excreted in the 5-min observation period was pooled with the total number of urinations, in view of the infrequency of the latter, prior to analysis. An analysis of variance revealed significant differences in emotionality between the dietary lead conditions, as shown by transformed mean values of $1.52,1.05$, and .82 for the groups receiving $50 \mathrm{ppm}, 25 \mathrm{ppm}$, and $0 \mathrm{ppm}$ lead acetate, respectively $[\mathrm{F}(2,14)=42.290, \mathrm{p}<.001]$. Subjects receiving $50 \mathrm{ppm}$ lead acetate were found to have exhibited significantly greater emotionality than either the group receiving $25 \mathrm{ppm}$ lead acetate $[\mathrm{t}(14)=$ $2.752, \mathrm{p}<.02]$ or the group receiving $0 \mathrm{ppm}$ lead acetate $[\mathrm{t}(14)=4.060, \mathrm{p}<.005]$. No significant differences in emotionality were found between the group receiving $25 \mathrm{ppm}$ lead acetate and that receiving $0 \mathrm{ppm}$ lead acetate $[t(14)=1.38, p>.10]$. All subjects, regardless of treatment, showed significantly decreasing emotionality across days of testing, as evidenced by transformed trial means of $1.41,1.22,1.14, .94$, and .82 $[F(4,56)=3.179, p<.02]$.

\section{DISCUSSION}

None of the classical overt effects of lead poisoning such as stunted growth or weight retardation were produced in the rat at these levels of exposure. Moreover, since lead acetate was administered postnatally in the drinking water, the possibility of inducing the confounding factors derived from injection procedures or intubation was eliminated. Early stress and trauma associated with such invasive methods may induce behavioral aberrations later in life (Hastings et al., 1977).

The significance of the failure to find substantial differences in food consumption, lead acetate or water consumption, and weight gain was pointed out by Rafales et al. (1979). Various studies that reported increased locomotor activity as a function of lead exposure utilized dosage regimens that produced weight retardation (Sauerhoff \& Michaelson, 1973; Silbergeld \& Goldberg, 1974a, 1974b). Such a retardation of growth has previously been shown to alter locomotor responses (Castellano \& Oliverio, 1976). The effects of chronic lead exposure that were described by Hastings et al. (1977), Rafales et al. (1979), and Sobotka and Cook (1974) as regards the failure to find evidence of hyperactivity have been confirmed in this investigation, although employing a postnatal lead-exposure regimen.

The results of the present investigation indicate that the increased emotionality induced by lead ingestion in weaning rats is similar to that induced in neonatal rats. Hyperactivity and increased aggressiveness have been reported in perinatally exposed animals (Sauerhoff \& Michaelson, 1973; Silbergeld \& Goldberg, 1974a, 1974b; Winneke et al., 1977). The current findings, however, must be considered as potentially indicative of lead intoxication with concomitant elevated soft-tissue body burdens concurrent with behavioral testing, and they do not indicate whether the aberrations in emotionality that were found will persist beyond the period of lead exposure.

\section{REFERENCES}

Brown, D. R. Neonatal lead exposure in the rat: Decreased learning as a function of age and blood lead concentrations. Toxicology and Applied Pharmacology, 1975, 32, 628-637.

Brown, S., Dragann, N., \& Vogel, W. H. Effects of lead accetate on learning and memory in rats. Archives of Environmental Health, 1971, 22, 370-372. 
Castellano, C., \& Oliverio, A. Early malnutrition and postnatal changes in brain and behavior in the mouse. Brain Research, 1976, 101, 317-325.

Castellino, N., \& Aloj, S. Kinetics of the distribution and excretion of lead in the rat. British Journal of Industrial Medicine, 1964, 21, 308-314.

DAvid, O. J. Association between lower level lead concentrations and hyperactivity in children. Environmental Health Perspectives, 1974, 7, 17-25.

Driscoll, J. W., \& Stegner, S. E. Behavioral effects of chronic lead ingestion on laboratory rats. Pharmacology, Biochemistry and Behavior, 1976, 4, 411-417.

Geist, C. R., \& Mattes, B. R. Behavioral effects of postnatal lead acetate exposure in developing laboratory rats. Physiological Psychology, 1979, 7, 399-402.

Golte R, M., \& Michaelson, I. A. Growth, behavior, and brain catecholamines in lead exposed neonatal rats: A reappraisal. Science, 1975, 187, 359-361.

Hastings, L., Cooper, G.P., Bornschein, R. L., \& Michaelson, I. A. Behavioral effects of low level neonatal lead exposure. Pharmacology, Biochemistry and Behavior, 1977, 7, 37-42.

KIRK, R. E. Experimental design: Procedures for the behavioral sciences. Belmont, Calif: Brooks/Cole, 1968.

LANThORN, T., \& IsAacson, R. L. Effects of chronic lead ingestion in adult rats. Physiological Psychology, 1978, 6, 93-95.

Rafales, L. S., Bornschein, R. L., Michaelson, I. A., Loch, R. K., \& BARKeR, G. F. Drug induced activity in lead-exposed mice. Pharmacology, Biochemistry and Behavior, 1979, 10 , 95-104.

Reiter, L. W., Anderson, G. E., Laskey, J. W., \& Cahill, D. F. Developmental and behavioral changes in the rat during chronic exposure to lead. Environmental Health Perspectives, $1975,12,119-123$.

Sauerhoff, M. W., \& Michaelson, I. A. Hyperactivity and brain catecholamines in lead-exposed developing rats. Science, 1973, 182, 1022-1024.

Silbergeld, E. K., \& Goldberg, A. M. Hyperactivity: A leadinduced behavioral disorder. Environmental Health Perspectives, 1974, 7, 227-232. (a)

Silbergeld, E. K., \& Goldberg, A. M. Lead-induced behavioral dysfunction: An animal model of hyperactivity. Experimental Neurology, 1974, 42, 146-157. (b)

Snowdon, C. T. Learning deficits in lead-injected rats. Pharmacology, Biochemistry and Behavior, 1973, 1, 599-603.

SовоткA, T. J., \& Соoк, M. P. Postnatal lead acetate exposure in rats: Possible relationship to minimal brain dysfunction. American Journal of Mental Deficiency, 1974, 79, 5-9.

Winne ke, G., Brockhaus, A., \& Baltissen, R. Neurobehavioral and systemic effects of longterm blood lead-elevations in rats. I. Discrimination learning and open field behavior. Archives of Toxicology, 1977, 37, 247-263.

(Received for publication March 27, 1980.) 